\title{
Propagación del Lisianthus cv. Azul por esquejes en macetas de turba bajo nebulización, con distintas concentraciones de ácido $\beta$-indolbutírico, en el Valle de Azapa
}

\author{
Propagation of Lisianthus cv. Blue by cuttings in peat pots under mist, \\ with different concentrations of $\beta$-indole butyric acid \\ in the Azapa Valley
}

Eugenio M. Sotomayor León ${ }^{1}$; Marcela R. Escobar Tolosa ${ }^{2}$; Carla A. Rosas Guerra ${ }^{3}$

\begin{abstract}
RESUMEN
Con plantas de Lisianthus (Eustoma grandiflorum) cv. Abc 2-3 Blue Rim, se realizaron pruebas de enraizamiento de esquejes provenientes del raleo de las plantas madre. Los esquejes fueron tratados con tres niveles de ácido $\beta$-indolbutírico (250, 500 y 1.000 ppm). Las plantas fueron mantenidas bajo nebulización en el invernadero de la Facultad de Ciencias Agronómicas de la Universidad de Tarapacá, en el Valle de Azapa. Los resultados indican que el esqueje es una excelente alternativa de propagación, que alcanza entre un 92 y $100 \%$ de éxito, para los diferentes niveles de auxina utilizados.
\end{abstract}

Palabras clave: Eustoma grandiflorum, flor de corte, propagación, enraizamiento, auxinas

\begin{abstract}
Tests of rooting of Lisianthus (Eustoma grandiflorum) cv. Abc 2-3 Blue Rim cuttings, obtained by prunning were performed. The cuttings were treated with three levels of $\beta$-indolbutiric acid $(250,500$ and $1.000 \mathrm{ppm})$. The plants were maintained under mist, in the Ciencias Agronómicas greenhouse belonging to the Universidad de Tarapacá, in Azapa Valley of Northern Chile. The results indicate that the rooting of cuttings is an excellent propagation alternative that reached between a 92 and $100 \%$ success for the different levels of auxin used.
\end{abstract}

Key words: Eustoma grandiflorum, cutting, spread, rooting, auxin.

\section{Introducción}

El Lisianthus es conocido hoy por su cultivo para flor cortada. En la actualidad existe una tendencia al alza en su producción, por ser una especie novedosa, vistosa, con muy buena duración en florero y un precio final ajustado. Hasta la fecha existe escasa información sobre las técnicas de propagación para esta especie, siendo la propagación por semilla la más utilizada y conocida.

Entre las prácticas agronómicas que se realizan al cultivo, el raleo de varas se considera parte esencial, porque sirve para seleccionar los tallos más vigorosos. Si el raleo no se realiza se obtiene un aumento del número de varas, pero éstas son más delgadas y cortas, y no tienen valor comercial.

\section{Materiales y Métodos}

El ensayo se realizó en la Estación Experimental de la Facultad de Ciencias Agronómicas de la Universidad de Tarapacá, ubicada en el km 12 del Valle de Azapa, Arica.

Se utilizaron plantas madres de Lisianthus cv. Azul (Eustoma grandiflorum (Raf.) cv. Abc 2-3 Blue Rim), provenientes de semilla. Los esquejes

\footnotetext{
1 Ingeniero Agrónomo, Dr. Universidad de Tarapacá. Fac. Cs. Agronómicas. Depto. Producción Agrícola, Arica, Chile. E-mail: esotomay@uta.cl

2 Ingeniero Agrónomo, M.Sc. Universidad de Tarapacá. Fac. Cs. Agronómicas. Depto. Recursos Ambientales, Arica. Chile. E-mail: mrescobart@uta.cl

3 Ingeniero Agrónomo.
} 
fueron extraídos de las plantas madres mediante raleo, labor cultural común para este tipo de flor de corte, que consiste en eliminar las ramillas de menor diámetro.

Se dejó un par de nudos libres de hojas en la parte basal de los esquejes, y dos pares de hojas en el tercio superior del brote, por encima del cual se cortó el brote. Antes de proceder al tratamiento hormonal, los esquejes fueron tratados con una solución de Captan (3.500 ppm), para evitar algún posible ataque de hongos.

La aplicación de auxina (ácido $\beta$-indolbutírico; IBA) se realizó sumergiendo los dos centímetros básales de cada esqueje, en una solución hidroalcohólica al 50\%, en concentraciones de 250, 500 y 1.000 ppm, durante 5 segundos. Luego, los esquejes fueron mantenidos al aire durante 10 minutos, para permitir la evaporación del disolvente y asegurar una dosificación adecuada del IBA. Se utilizó un testigo sin aplicación de auxina.

Para el enraizamiento se utilizaron vasos de turba de $114 \mathrm{~cm}^{3}$, como sustrato se empleó una mezcla de turba $(67 \%)$ y perlita (33\%). Para prevenir el desarrollo de hongos las macetas se desinfectaron con Previcur N $\left(20 \mathrm{~cm}^{3} / \mathrm{L}\right)$. Las plantas enraizadas se colocaron con el vaso de turba en la mesa de propagación, utilizando perlita como sustrato. La temperatura de fondo fue controlada con un termostato entre $\operatorname{los} 25^{\circ} \mathrm{C}$ a $27^{\circ} \mathrm{C}$ y la temperatura ambiental se mantuvo en un rango de 26 a $28^{\circ} \mathrm{C}$, de acuerdo a lo señalado por Sotomayor (1999).

El riego se aplicó durante el día desde las 08:00 hasta las 18:00 horas. La nebulización se realizó mediante boquillas atomizadoras, situadas $35 \mathrm{~cm}$ por encima del nivel de las hojas, con intervalos de riego de 20 minutos y una duración de 12 segundos cada vez.

En esta primera contribución se evaluó el porcentaje de enraizamiento de Lisianthus cv. Azul propagado vegetativamente, en macetas de turba bajo nebulización, con distintas concentraciones de IBA. A los 60 días se hizo el recuento del número de plantas con raíces en cada uno de los tratamientos.

Se utilizó un diseño completamente aleatorizado, con cuatro tratamientos y tres repeticiones. $\mathrm{La}$ unidad experimental fue cinco plantas. Los resultados obtenidos se sometieron a un Análisis de Varianza y al Test de Rangos Múltiples de Duncan ( $\mathrm{p} \leq 0,05)$. Previo al análisis estadístico, los datos expresados como porcentaje fueron estandarizados utilizando la Transformación Angular de Bliss.

\section{Resultados y Discusión}

En la Figura 1 se muestra el porcentaje de enraizamiento de esquejes. Los resultados indican que las concentraciones con IBA T3 (1000 ppm)

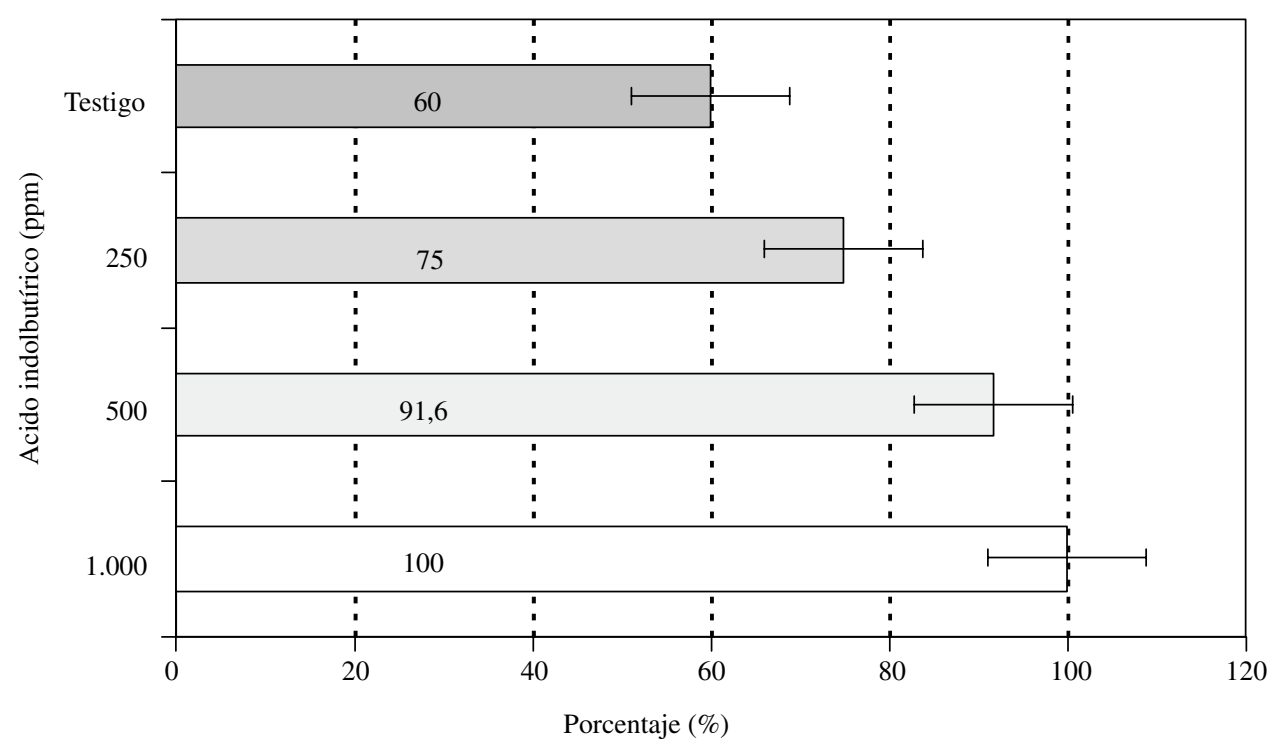

Figura 1. Porcentaje de enraizamiento esquejes de Lisianthus cv. Azul, tratados con diferentes concentraciones de ácido $\beta$-indolbutírico. 
y T2 (500 ppm) no presentan diferencias significativas entre ellos, con un 100 y $92 \%$ de enraizamiento respectivamente, pero sí existen diferencias significativas $(\mathrm{p} \leq 0,05)$ del $\mathrm{T} 3$ frente al T1 (250 ppm) y T0 (testigo). A su vez, entre los tratamientos T1 y T0 no presentan diferencias significativas.

Melgares (1996) señala que la reproducción del Lisianthus se realiza normalmente por semilla, aunque también se puede hacer por esqueje o por cultivo "in vitro" de tejidos. Maldonado y Contreras (2005) agregan que el tiempo de germinación y crecimiento de la radícula se extiende por 10 a 14 días y, desde el trasplante hasta la obtención de los plantines varía de 10 a 19 semanas dependiendo la época se siembra, completando así 70 a 126 días. Por otra parte, Melgares (1997) indica que el ciclo de las variedades de macetas es muy corto, oscila entre ocho a diez semanas (55 a 70 días), desde la plantación de las plantitas en la maceta, hasta su venta con el cincuenta por ciento de las flores abiertas. En cambio, propagándola por esquejes se obtienen plantas a los 60 días.

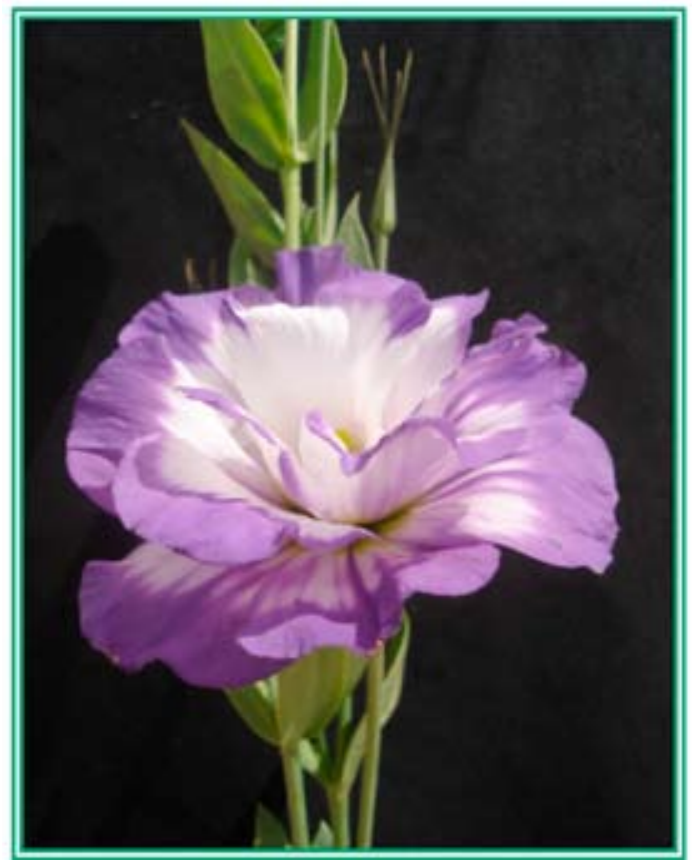

Figura 2. Lisianthus (Eustoma grandiflorum) cv. Azul.

\section{Conclusiones}

Los mejores resultados se obtuvieron con concentraciones de IBA de 1000 y 500 ppm, equivalentes a 100 y $92 \%$ de enraizamiento, respectivamente.

Con este sistema de propagación se aprovecha el material vegetal del raleo, y se obtiene mayor precocidad en el desarrollo de la planta.
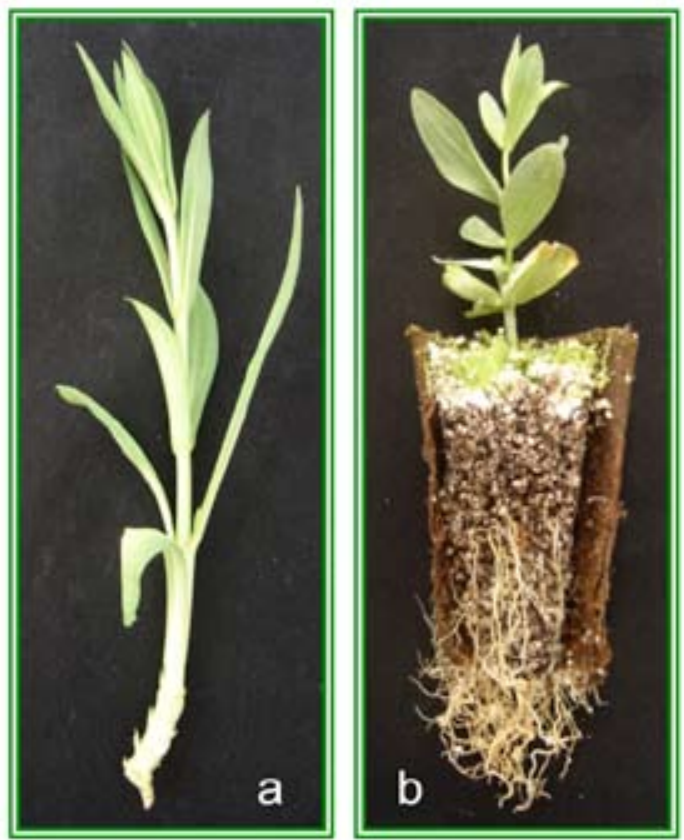

Figura 3. a) Esqueje; b) Esqueje enraizado en maceta de turbaperlita.

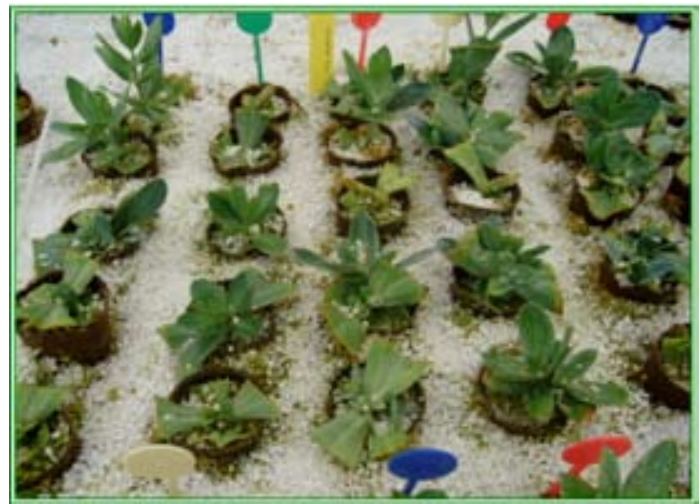

Figura 4. Vista general del ensayo experimental de esquejes de Lisianthus cv. Azul propagados vegetativamente bajo distintas concentraciones de ácido $\beta$-indolbutírico, bajo nebulización. 


\section{Literatura Citada}

Maldonado, P.; Contreras, J.

2005 Lisianthus, producción de plántulas. Tierra Adentro. (INIA-CHILE) 60: 39-41.

Melgares, J.

1996 El Cultivo de Lisianthus (II Parte). Horticultura. Revista de Hortalizas, Flores, Plantas Ornamentales y Viveros. Vol. XV - No 5, julio, pp. 47-50.
Melgares, J.

1997 Cultivo de Lisianthus en maceta Horticultura. Revista de Hortalizas, Flores, Plantas Ornamentales y Viveros. Vol. XVI- No 7, octubre, pp. 13-16.

Sotomayor, L. E.

1999 Propagación del olivo Olea europaea L. cv. Azapa por estaquillado semileñoso bajo diferentes medios de enraizamiento. Idesia. Arica (Chile) 17: 9-17. 